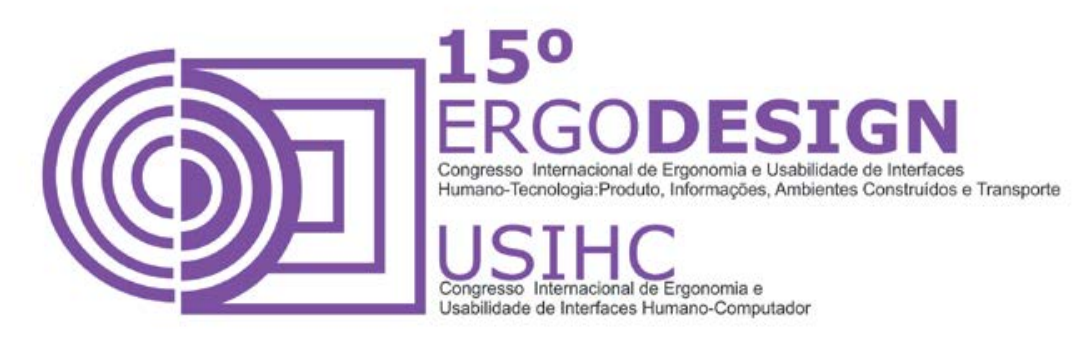

\title{
INTERAÇÃO REATIVA E SUBJETIVIDADE EM SITES DE REDES SOCIAIS
}

\section{REACTIVE INTERACTION AND SUBJECTIVITY IN SOCIAL NETWORK SITES}

\author{
NOGUEIRA, Hamilton Garcia (1); \\ GONÇALVES, Berenice Santos (2); \\ PEREIRA, Alice T. Cybis (3); \\ (1) UFSC, Mestrando em Design \\ e-mail: hamiltongn@gmail.com \\ (2) UFSC, Dra. em Engenharia de Produção \\ e-mail: berenice@cce.ufsc.br \\ (3) UFSC, PhD em Arquitetura \\ e-mail: acybis@gmail.com
}

\begin{abstract}
RESUMO
O "curtir" é uma das interações mediadas por sites de redes sociais (SRSs) que carrega significados e desdobramentos que vão além de um clique. Este artigo apresenta uma reflexão em torno do conceito de interação reativa, buscando uma ressignificação no âmbito dos SRSs. Buscou-se conceituar interface, interação e comunicação mediada por computador. A partir de um método descritivo, observou-se a funcionalidade "curtir" no Facebook. Percebe-se um reposicionamento da interação reativa, que se limitava às interações sistemáticas, vinculadas principalmente às funcionalidades dos sistemas. Como característica marcante de SRSs, a interação reativa adquire maior relevância para o campo do design de interfaces.
\end{abstract}

Palavras-chave: Interação, interface, sites de redes sociais

\section{ABSTRACT}

Mediated by social networking sites (SNSs) the "like" is an interaction that carries meanings and consequences beyond just a click. This article presents a reflection on the reactive interaction concept, aiming a reframing at the SNSs context. To that end, interface, interaction and computer-mediated communication was described. Using a descriptive method, the functionality "like" was observed on 


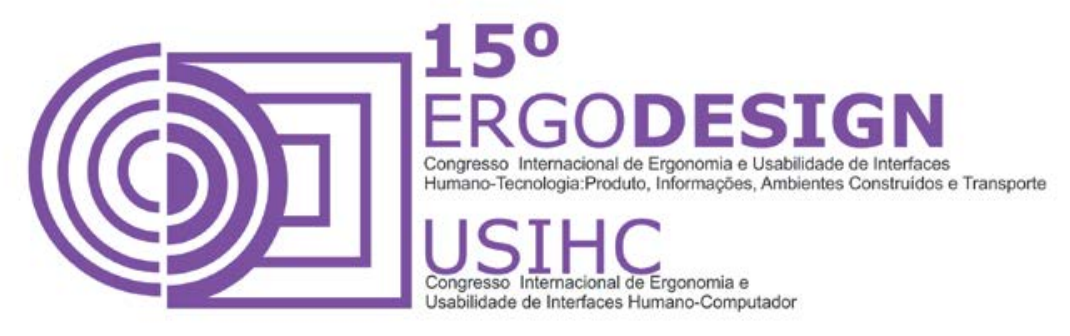

Facebook. Usually restricted to systematic interactions, mainly linked to system's functionality, the reactive interaction seems to reposition itself. As a hallmark of SNSs, the reactive interaction acquires more relevance for the interface design field.

Keywords: interaction; interface; social network sites

\title{
1. INTRODUÇÃO
}

Quantas publicações um usuário de sites de redes sociais (SRSs) "curte" em um dia? Realizar esse tipo de interação é tão simples que se tornou um hábito, quase automático, que se repete inúmeras vezes, em diversos contextos em SRSs. Para entender esse tipo de interação temos que refletir sobre o seu contexto.

Popularizados na era da Web 2.0, os SRSs mudaram de tal maneira o uso da internet que quase não é possível se fazer uma distinção entre os dois universos. Com interfaces atrativas, fáceis de usar e repletas de funcionalidades para a comunicação e a interação social, os SRSs, considerados um tipo de mídia social, estão entre os mais acessados no Brasil e no mundo. A respeito do termo "rede social" é importante ressaltar que se trata de "uma metáfora para observar os padrões de conexão de um grupo social, a partir das conexões estabelecidas entre os diversos atores" (RECUERO, 2009, p. 24), ou seja, sua existência não depende de qualquer tipo de site ou mídia, pois se aplica ao mundo offline, tratando das relações humanas. Facebook $^{1}$, $_{\text {witter }}{ }^{2}$ e Instagram ${ }^{3}$ são alguns exemplos de SRSs.

\begin{abstract}
Essas ferramentas pertencem à categoria cada vez mais popular dos "sites de rede social", ou seja, ferramentas que proporcionam a publicação e construção de redes sociais. As redes sociais são as estruturas dos agrupamentos humanos, constituídas pelas interações, que constroem os grupos sociais. Nessas ferramentas, essas redes são modificadas, transformadas pela mediação das tecnologias e, principalmente, pela apropriação delas para a conversação. (RECUERO, 2012, p. 15).
\end{abstract}

Assim, a interatividade é um dos pontos fortes desse tipo de serviço, pois é através da interação com suas interfaces gráficas que ocorre a comunicação entre seus usuários. Na categorização proposta por Primo (2001), a interação com uma interface pode ser reativa, quando o sistema oferece escolhas pré-definidas, ou mútua, quando o usuário tem maior participação e liberdade comunicativa - com o sistema e com outros usuários.

Se por um lado o primeiro tipo parece limitante, percebe-se que em SRSs, especialmente no Facebook, uma simples interação de um clique possui potencial expressivo: o ato de "curtir" um link, uma página, uma foto, etc., revela traços da personalidade do interagente e de suas relações com os contatos de sua rede. Considerando os estudos sobre interação e

\footnotetext{
${ }^{1}$ http://facebook.com

${ }^{2}$ http://twitter.com

${ }^{3}$ http://instagram.com
} 


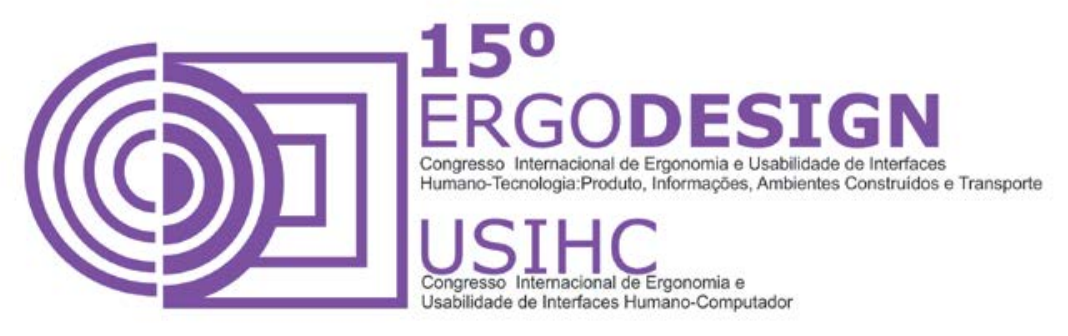

comunicação mediada por computador, busca-se identificar qual é o papel da interação reativa na dinâmica das mídias sociais, especialmente em SRSs. Para chegar a esse objetivo, pretende-se analisar o processo da interação "curtir" na perspectiva de suas funções práticas e subjetivas.

\section{INTERFACE}

O uso de computadores, smartphones e tablets já faz parte da rotina contemporânea. Tarefas escolares, acadêmicas, profissionais, sociais e de entretenimento são facilitadas e potencializadas por meio desses dispositivos. Fazer uma busca na internet, escrever em um editor de texto, assistir a um vídeo ou ouvir uma música são só algumas das infinitas possibilidades ofertadas pela tecnologia, que evolui constantemente. De maneira simplificada, os aparelhos que as pessoas utilizam em suas rotinas são baseados em dois sistemas que se complementam: hardware, a parte física (processador, teclado, tela, etc.), e software, a parte digital (sistema operacional, navegador, página na internet, etc.). Em ambos os casos, a manipulação por pessoas se dá através de interfaces, que funcionam como mediadoras. A respeito dos softwares de computadores, Johnson (2001, p.24) explica que "a interface atua como uma espécie de tradutor, mediando entre as duas partes, tornando uma sensível para a outra".

Atualmente o termo computador não se aplica apenas aos desktops, mas a todos os aparelhos já citados e a muitos outros que ainda podem surgir. E o conceito de interface também não se restringe às tecnologias de informação e comunicação, considerando que até mesmo um forno micro-ondas possui uma interface, que traduz a complexidade de seu sistema em códigos compreensíveis por pessoas comuns. Falando os dois "idiomas", as interfaces tornam possível a relação entre pessoas e máquinas. É nesse sentido que Santaella (2013, p. 57) conceitua interface e a dependência desta para a existência da dita interatividade. Segundo a autora, para que pessoas e máquinas entrem em um processo de conversação é preciso que haja esse recurso na superfície.

Desse modo, a interface atua como uma tradutora dos estímulos e sentidos, para que seja possível a manipulação direta ou indireta de hardware e software. Santaella (2013, p.57) lembra que há também interfaces entre componentes das máquinas. O mouse, por exemplo, é um hardware periférico que permite, entre outras ações, captar o movimento da mão humana, transpondo-o para o cursor presente no sistema operacional, que é um software. Pode parecer simples, mas estão implícitas nesse processo diversas interfaces, ou seja, conexões entre sistemas, para que se cumpra a função desejada.

$\mathrm{Na}$ conexão entre sistemas e pessoas há um obstáculo. A maioria dos seres humanos não é capaz de entender as sequências de 0 e 1 que formam a linguagem dos softwares, conforme explica Johnson (2001, p.25). Por esse motivo, os números e linhas de código são substituídos pelas metáforas que são elemento básico da interface gráfica contemporânea. Da mesma forma que os botões da interface física do forno micro-ondas traduzem os códigos do sistema, para que estes possam ser entendidos pelo usuário do eletrodoméstico, a interface gráfica traduz seus comandos em elementos gráficos exibidos na tela. Frequentemente essas metáforas 


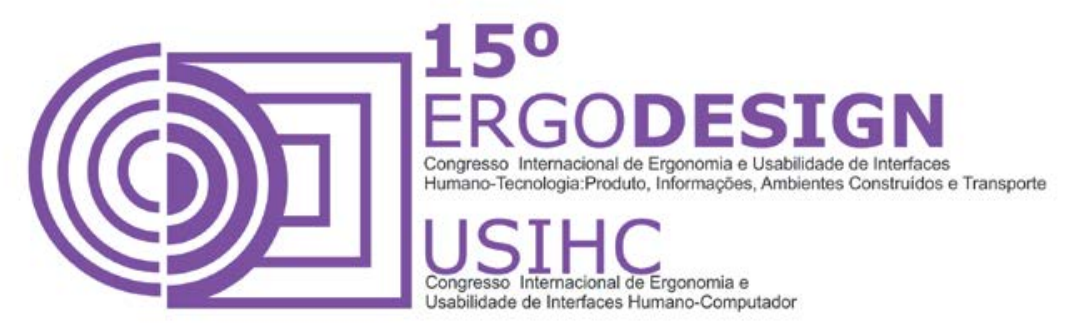

remetem a objetos físicos, como um botão. A validade das metáforas no paradigma atual da interface tem sido questionada e uma possível substituição por outras expressões idiomáticas tem sido discutida (COOPER, 2011, p. 272). Contudo, não há sinais de que as metáforas serão descartadas totalmente em um futuro próximo.

\subsection{Interação e Comunicação Mediada por Computador}

A manipulação das interfaces gráficas é tratada na literatura como interação, relação entre usuário e computador que depende da interface para existir. O conceito de interatividade é difundido nas áreas de ciências da computação, design e comunicação. Porém, há algumas interpretações e ainda uma diferença conceitual entre dois termos. Segundo Tori (2010, p. 5), interação é a "ação exercida entre dois elementos, na qual haja interferência mútua no comportamento dos interatores", enquanto interatividade se trata da "percepção da capacidade, ou potencial, de interação propiciada por determinado sistema ou atividade". O autor explica, ainda, que independente da ocorrência de atividades de interação, a interatividade pode estar presente como característica de um ambiente, tecnologia, sistema ou atividade. Assim, a possibilidade de haver interação já caracteriza a interatividade em si.

Os termos interação-homem-máquina (IHM) e interação-humano-computador (IHC) têm sido utilizados para se referir a essas trocas entre as pessoas e os computadores, e consequentemente seus softwares. Por focarem na interação entre pessoas e computadores, não abordam detalhadamente a comunicação entre pessoas, por meio do computador. Nesse sentido, a perspectiva da comunicação mediada por computador (CMC) emerge, complementando as teorias anteriores. A IHC continua no processo, mas a CMC foca nas relações humanas proporcionadas por ela. Recuero estuda a CMC através das apropriações feitas pelos usuários. Segundo a autora, "a própria história da internet confunde-se com a história da apropriação conversacional da técnica que the deu origem." (RECUERO, 2012, $p$. 22). Dessa maneira, fica claro que, além da internet influenciar na maneira como as pessoas se comunicam, as pessoas desempenharam um papel importante para a evolução da internet como ferramenta comunicacional.

A CMC evolui paralelamente às tecnologias. Conforme se popularizam recursos de texto, áudio e vídeo, surgem também as apropriações para a comunicação. Por um lado a tendência é a exploração das mídias para conversas que imitam a interação presencial, como em videoconferências, de forma oralizada e imediata. Por outro, a comunicação não verbal ganha novas formas de expressão, para além das imitações da conversação face a face. Emoticon, termo da língua inglesa resultado da união das palavras emotion e icon, são um exemplo consagrado da comunicação não verbal. Para Recuero (2012, p.46), apesar de haver registros anteriores à CMC, foi com a internet que os emoticons se popularizaram e evoluíram para a forma atual. Recentemente interações simples, de apenas um clique, estão explorando o mesmo sentido de expressão não verbal e ganhando destaque na web. Opções como "curtir" 


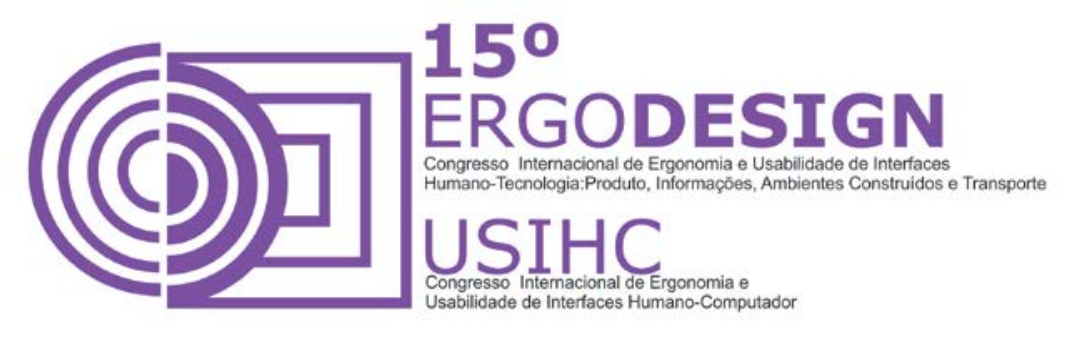

(ou "gostei" em alguns casos, como no Youtube ${ }^{4}$ ) são praticamente um padrão lançado por SRSs e aderido por outros tipos de site. Como são opções limitadas pelo sistema, essas interações se configuram como reativas, conforme o que Primo define:

As interações reativas, por sua vez, são marcadas por predeterminações que condicionam as trocas. Diferentemente das interações mútuas (cuja característica sistêmica de equifinalidade se apresenta), as reativas precisam estabelecer-se segundo determinam as condições iniciais (relações potenciais de estímulo-resposta impostas por pelo menos um dos envolvidos na interação) [...] (Primo, 2008, p. 228).

O autor explica que podem ocorrer interações reativas entre computadores. Nesse caso a interação funciona de forma lógica e matemática, diferente do que ocorre nas interações entre pessoas mediadas pelo computador. Recuero desenvolve uma reflexão a respeito da tipologia criada por Primo:

Embora essas interações não sejam mútuas, elas têm impacto social, já que têm também reflexos nos dois lados da relação comunicativa. Se alguém aceita ser amigo de alguém no Orkut, por exemplo, há um reflexo no sistema (as pessoas são unidas por uma conexão) e um reflexo no indivíduo (cada um dos interagentes terá mais um "amigo", que poderá ter acesso a seus dados pessoais e enviar mensagens). Do mesmo modo, ao entrar em uma comunidade, o ator tem um reflexo sobre a mesma (já que sua presença será notada pelo aparecimento de sua foto e nome dentro do sistema do grupo) e sobre os demais atores, que virão a vê-lo. (Recuero, 2009, p. 33).

Apesar das nomenclaturas e diferenças técnicas do Orkut ${ }^{5}$ e do Facebook, o conceito acima serve para ambos os sites, bem como outros tantos em atividade: Twitter, Instagram, Pinterest ${ }^{6}$, Tumblr $^{7}$, Google Plus ${ }^{8}$, etc. No caso do Facebook, as relações entre perfis, páginas, grupos e eventos criam essas conexões com impactos sociais, muitas vezes através da interação reativa. Quando um usuário "curte" uma foto ou um post, ocorre uma (re)ação social. A princípio, o significado e os resultados dessa interação parecem claros: eu gostei dessa publicação e estou demonstrando isso através desse "curtir". Todavia, esse clique gera registros no Facebook, significando algo para o seu sistema, e também para o(s) receptor(es), não necessariamente de maneira coerente com as intenções do emissor. Como funciona a interação "curtir", suas consequências e a subjetividade envolvida são alguns dos aspectos a serem discutidos.

\footnotetext{
${ }^{4}$ http://youtube.com

${ }^{5}$ http://orkut.com - Encerrado em setembro de 2014.

${ }^{6} \mathrm{http}: / /$ pinterest.com

${ }^{7}$ http://tumblr.cm

${ }^{8}$ http://plus.google.com
} 


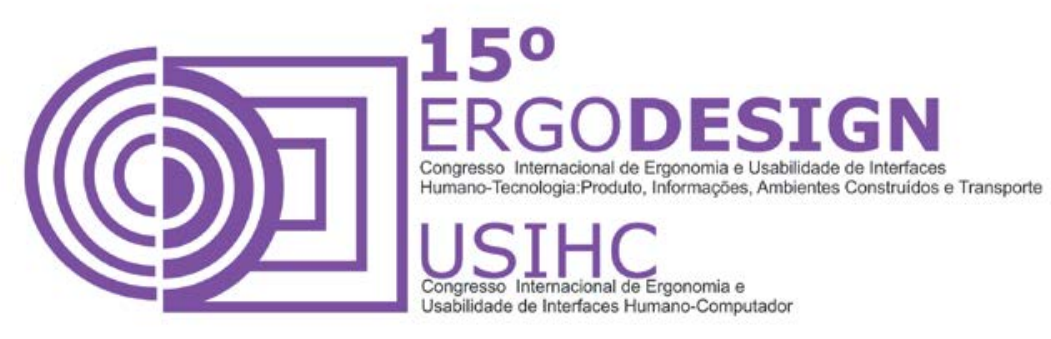

\subsection{Interação e Subjetividade}

Conforme foi tratado no tópico anterior, para que a interação efetivada entre uma pessoa e um computador seja reativa deve haver opções pré-determinadas pelo sistema. Quando um usuário se depara com a pergunta "tem certeza que deseja fechar?", em um software qualquer, geralmente são exibidas duas opções: "sim" e "não". Ao clicar na opção "sim", o usuário está dando um comando na interface, que é traduzido para o sistema. Todo o resto é trabalho do computador, que executa as tarefas para que a ação seja cumprida. Na CMC esse processo fica mais complexo, pois envolve uma segunda pessoa, ou ainda outras, além da própria interface. Primo explica que esta também pode ser considerada como um ator nessa relação.

Assumindo-se os princípios da Teoria Ator-Rede, um meio digital precisa ser interpretado como um "mediador" ao fazer diferença nas associações. Uma conversa entre dois colegas de trabalho através do e-mail seria diferente se fosse mantida via Twitter. E também não seria a mesma se ocorresse através de comentários em um blog de acesso público. Como se pode observar, a mídia nestes casos não é um mero condutor de dados. (Primo, 2012, p. 633).

Conforme ilustra a Figura 1, para que o ator A se comunique com o B ele deve interagir com a interface, através das opções disponibilizadas pela mesma, para que então o ator $\mathrm{B}$ receba a mensagem (ou perceba aquela interação) e possa responder ou não a ela, recomeçando o processo. A Figura 1 demonstra, de maneira genérica, esse processo em que a interface faz a mediação das interações entre os usuários.

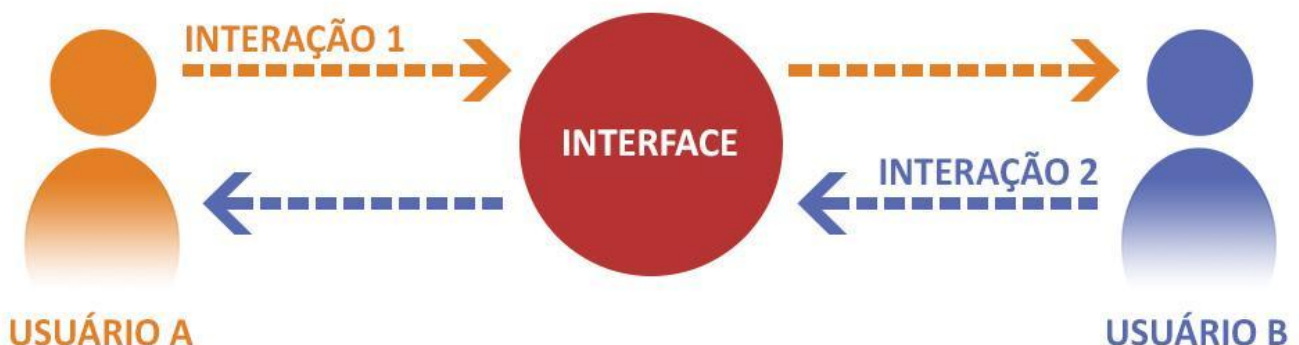

Figura 1 - Esquema simplificado da mediação de interações por uma interface Fonte: Os autores.

É importante destacar que essas interações (Figura 1) podem ocorrer (1) de forma síncrona ou assíncrona, (2) de um-para-um ou de um-para-muitos, e (3) sem obrigatoriedade de resposta, ou seja, qualquer contra interação de outros usuários que receberam ou visualizaram a interação original. 


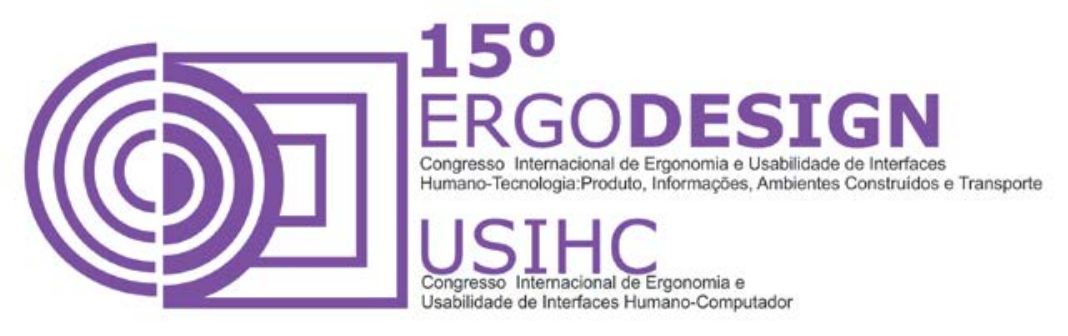

Quando Primo diz que a mídia não é apenas um condutor de dados, explicita a influência da interface sobre a conversa e seu conteúdo. No Twitter, por exemplo, o número de caracteres é limitado, resultando em um maior número de mensagens mais curtas. Em uma conversa por email não há esse tipo de limitação, mas o conteúdo das mensagens se mantém em um ambiente restrito aos destinatários. Em ambos os casos são apenas características que podem ser consideradas positivas ou negativas, dependendo do contexto de uso. De qualquer maneira elas acabam interferindo na comunicação, como quando um usuário apenas "curte" a publicação de um amigo que passou no vestibular, deixando de escrever um comentário com uma mensagem. Por um lado pode parecer negativo, um corte de discurso. Por outro, pessoas não tão íntimas, que não escreveriam uma mensagem, encontram uma maneira de interagir e se fazer, de certa forma, presentes.

No mundo digital as pessoas interagem entre si e com objetos, tal qual ocorre no mundo real. Podemos fazer a leitura de um texto, conversar com um amigo, etc. Essas interações ocorrem de forma direta e síncrona, mas existem ainda interações assíncronas que ocorrem entre pessoas. Ao postar um tweet, por exemplo, os indivíduos interagem com o sistema do Twitter, mas não se sabe quantas pessoas serão impactadas, e ainda, quais delas lerão de fato aquela mensagem. O número de seguidores, o horário da postagem, a reputação do emissor, o que mais estava acontecendo e sendo postado naquele momento, bem como as características de sua rede de contatos, são alguns dos fatores que vão influenciar nessa equação. Só poderemos mensurar parte do impacto através das reações àquele tweet que forem registradas. As contra interações, como o retweet, o "curtir" ou a resposta por menção, ficam registradas no sistema e confirmam que seus autores foram expostos ao primeiro tweet. Esse tipo de subjetividade é característica das mídias sociais. A ausência da verbalidade, expressada por texto ou som, não significa que não há comunicação. Segundo Recuero,

As conexões também são elementos conversacionais, provavelmente os mais claros quando pensamos em termos de redes sociais. Essas conexões constituem e são constituídas por conversações. Ao aceitar uma conexão no Facebook ou no Orkut, por exemplo, há uma conversação implícita. Ao dividir uma informação com sua rede, o ator cria uma expectativa de conversação. Embora as conexões nem sempre precisem de uma conversação para serem mantidas, elas são as grandes responsáveis pelo espalhamento característico das conversações em rede. (RECUERO, 2012, p. 143)

A autora explica que as interações nos SRSs podem ocorrer de forma síncrona ou assíncrona, e que são capazes de gerar elementos de valor, como capital social. Considerando que existem funcionalidades limitadas na interface desses sites, e que elas acabam moldando a forma como a interação acontecerá, fica evidente que a interface como interagente, de Primo, se aplica. O "curtir" do Facebook é um dos casos de interação sem precedentes em outros softwares.

Anteriormente, em outros SRSs era preciso um esforço maior para interagir com um dos contatos, através de um comentário com texto, mesmo que breve ou apenas com um emoticon. Ao clicar em "curtir", com apenas um clique interagimos e mandamos uma mensagem para o autor da postagem. Mas que mensagem é essa? A princípio pode-se interpretar conforme 0 


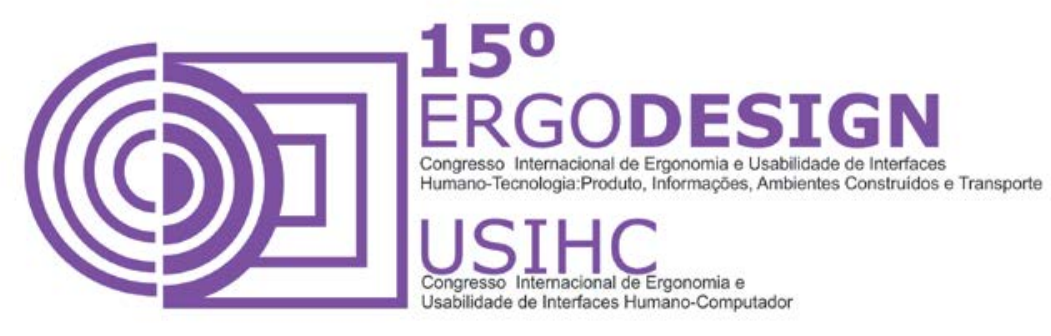

próprio rótulo, ou seja, a mensagem é que uma pessoa curtiu/gostou daquele post. Contudo, há motivações subjetivas e registros implícitos como consequência.

Santaella (2013) afirma que as pessoas utilizam seus perfis em SRSs como uma extensão da própria identidade. Formam-se "ambientes de convivência instantânea entre as pessoas" (2013, p. 115 e 117), e, portanto, há uma consciência de que as ações realizadas naquele ambiente representam seus autores, fragmentos de suas vidas, preferências pessoais, e suas opiniões. Contudo, esses ambientes não se tratam de uma replicação do mundo real, e neles há características sociais específicas. Recuero (2012, p. 132) chama atenção para o fato de que, ao contrário do que ocorre no meio offline, é possível possuir centenas de "amigos" nos SRSs, pois ali as conexões não se desgastam com o tempo ou com a falta de interação.

Outro aspecto citado é a possibilidade de se interagir com pessoas que não estão conectadas naquele momento. Assim, a via de troca de informações permanece sempre aberta. Um usuário que receba mensagens enquanto estiver offline tem acesso a todas as informações encaminhadas a ele na próxima conexão. Recuero (2012 p. 132) defende que "é muito mais rápido, simples e menos custoso difundir informações, espalhar ideias e conversar com outros atores que estão geograficamente distantes" por meio dos SRS. O "curtir" é uma interação reativa e, portanto, limitada, mas estabelece comunicação por meio desses eventos assíncronos. O número de curtidas também contribui para determinar a relevância daquele conteúdo para o sistema do Facebook.

Além da interação entre pessoas, cabe uma observação a respeito do que o "curtir" pode comunicar subjetivamente a respeito dos próprios usuários. Ehrenberg (2013) relata a pesquisa desenvolvida por Stillwell, pesquisador da Universidade de Cambrige, Inglaterra, que contou com 58.000 voluntários, usuários do Facebook. Um primeiro grupo forneceu informações privadas através de um aplicativo no Facebook e responderam a questionários sobre personalidade. Os pesquisadores compararam as respostas com a lista de páginas que os participantes curtiam no Facebook, para então utilizar os resultados para tentar prever características de um segundo grupo baseando-se apenas nas suas respectivas páginas curtidas. Foi constatado que é possível prever traços da personalidade de uma pessoa, como inclinação política, idade, gênero e orientação sexual, mesmo que não haja registro dessas informações no perfil. Os próprios mecanismos de publicidade da ferramenta, bem como de outros sites, partem do mesmo princípio na tentativa de exibir anúncios mais relevantes e aumentar a taxa de conversão em vendas para seus anunciantes. Apesar das limitações desse modelo e as fragilidades do estudo descrito por Ehrenberg, como suposições e o apoio em estereótipos, fica claro que a exposição causada por um simples clique é muito maior do que 0 "curtir" reflete em superfície.

Cabe ainda uma última reflexão a respeito da subjetividade do "curtir". Se sistemas automatizados utilizam da lógica e da matemática para a interpretação das interações dos usuários dos SRSs, as pessoas também podem tirar conclusões a respeito das publicações que seus contatos curtem. Em uma seleção para uma vaga de trabalho o conteúdo dos perfis em SRSs pode ser consultado pela empresa, impactando positivamente ou negativamente e, possivelmente, interferindo no processo seletivo. Nas relações pessoais também há um impacto 


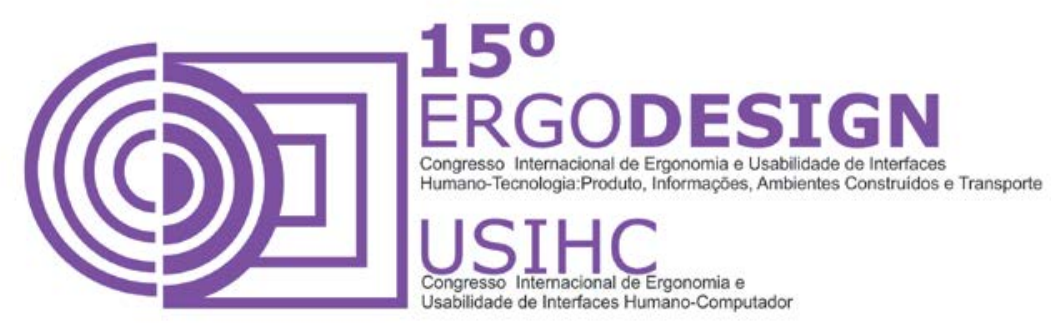

para ambos os lados, uma vez que o "curtir" pode ser motivo de sentimentos variados nos interagentes e também em meros observadores.

\section{CURTIR: MAIS QUE UMA INTERAÇÃO REATIVA}

Diariamente as pessoas executam inúmeras interações reativas, desde a chamada do elevador através de um botão físico até o play da música no celular, por meio de um botão da interface gráfica. Assim, a partir de uma abordagem descritiva, considera-se, a seguir, a comunicação através de interações de um clique em SRSs, como é o caso do "curtir".

Fundado em 2004, o Facebook esse é um dos sites de rede social mais utilizado no mundo, com mais 802 milhões de usuários ativos diariamente no mês de março de 2014 . Uma das características notáveis do site é justamente a ação "curtir", representada pela ilustração de uma mão fechada com o polegar erguido, fazendo referência ao gesto positivo:

Acabamos de introduzir uma forma simples de dizer aos seus amigos que você gosta do que eles estão compartilhando no Facebook, facilmente com apenas um clique. Sempre que for permitido que você comente no conteúdo de seus amigos você também terá a opção de clicar em "curtir" para dizer aos seus amigos exatamente isso: eu gosto disso. ${ }^{9}$

Após a introdução do botão "curtir" (originalmente like) pelo site em 2009, na intenção de possibilitar que os usuários pudessem interagir com os posts de seus contatos, sem necessariamente escrever uma mensagem, muitos outros sites aderiram à tendência e atualmente Twitter, Instagram, Tumblr, Pinterest e Google Plus possuem funcionalidades semelhantes. Trata-se de uma interação tão comum que a palavra "curtir" se popularizou também no vocabulário offline. Na nota de divulgação após o lançamento, por se tratar de um conceito novo, o Facebook utilizou o seguinte exemplo para explicar a novidade. Em um site de reviews de restaurantes, um usuário pode contar a sua experiência escrevendo uma resenha ou simplesmente marcar de 1 a 5 estrelas. Da mesma forma, no Facebook os comentários são como as resenhas e o "curtir" é como as estrelas. Tal explicação já não se faz necessária para grande parte dos usuários de SRSs, mas sua existência há não muito tempo denuncia a rapidez com que aceitamos e replicamos comportamentos na internet, às vezes sem perceber.

Antes da análise de algumas repercussões do "curtir", cabe uma breve descrição do funcionamento do site do Facebook. Cada usuário possui um perfil, que armazena e exibe as suas informações pessoais, postagens, fotos, contatos, etc. Todo texto, foto, vídeo, link ou evento criado pelo usuário gera uma publicação, que o Facebook denomina como "histórias". As histórias dos contatos e páginas do usuário alimentam o seu feed de notícias (newsfeed), que é o coração do site. Ali também são exibidas outras histórias, como as referentes a aplicativos e publicidade. Existem 3 opções para que usuários e páginas possam interajam com

\footnotetext{
${ }^{9}$ Tradução livre para nota oficial do Facebook,. Disponível em https://www.facebook.com/notes/facebook/i-like-this/53024537130. Acesso em março de 2014.
} 


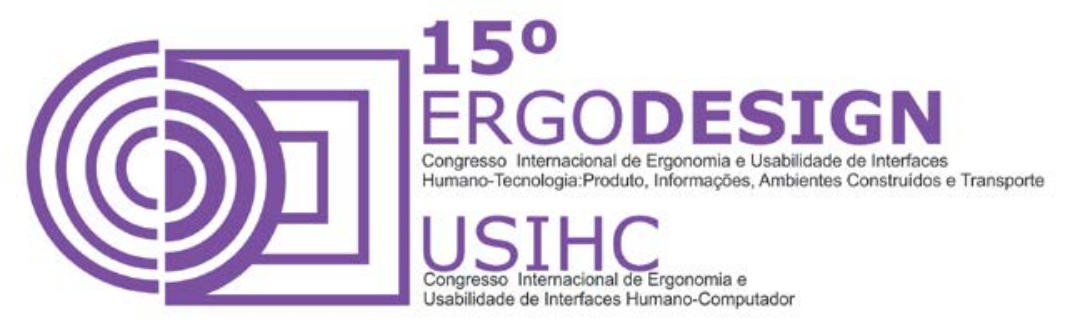

as histórias que visualizam: curtir, comentar e compartilhar. O foco dessa análise é a primeira delas, que apresenta ao menos 3 consequências imediatas.

O primeiro aspecto observado é a contagem do número de vezes em que aquela postagem foi "curtida", isto é, quantas pessoas "curtiram" aquela publicação, conforme a Figura 2. O número é exibido abaixo da publicação junto ao nome de alguns dos interagentes, caso haja conexão com quem está visualizando.

\section{Bruna $\quad$ e outras 12 pessoas curtiram isso.}

Figura 2 - Contagem exibida abaixo das publicações exibidas feed de notícias Fonte: Os autores.

O texto "outras X pessoas" (Figura 2) contém um hiperlink para a exibição de uma lista das pessoas que "curtiram" a publicação, com seus respectivos nomes, fotos e links para os perfis. A privacidade dessas informações depende da configuração do autor do post. Se o post for público, a lista de usuários que "curtiram" também será. Da mesma forma a lógica se aplica para posts disponíveis somente para os contatos do autor do post.

O segundo aspecto relativo ao "curtir" é a notificação (Figura 3). Cada vez que uma publicação no Facebook é "curtida", o autor da mesma recebe um aviso de que determinada pessoa, através de seu próprio perfil, realizou a interação. No caso de mais de uma interação do mesmo tipo em um post ocorre o agrupamento em uma única notificação:

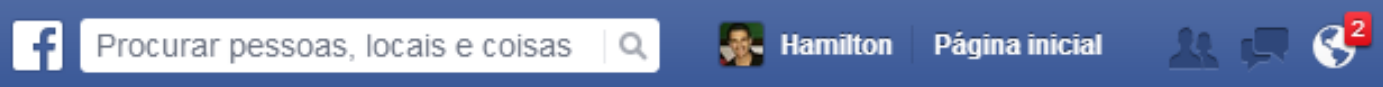 \\ Figura 3 - Contagem de notificações na barra superior da interface do Facebook Fonte: Os autores.}

Trata-se de uma informação privada. Somente o autor do post (ou comentário) recebe essa notificação. O ícone que representa um globo terrestre apresenta também outros tipos de notificação. O destaque em vermelho sobre o ícone aparece sempre que há uma nova notificação, exibindo o número de ocorrências.

O terceiro e último aspecto é a criação de uma espécie de história temporária a partir da interação (Figura 4). O surgimento pode ocorrer de forma arbitrária partindo do Facebook. O algoritmo do site calcula quando e para quem mostrar essa história no feed de notícias, baseado nas relações presentes nas redes sociais.

$\mathrm{Na}$ seguinte situação hipotética pode-se compreender o que ocorre. A usuária Carla "curtiu" uma foto de uma amiga, que não faz parte dos contatos de seu outro amigo, Arthur. Mesmo que ele não esteja conectado a essa amiga de Carla, poderá ser exibido entre as publicações que 


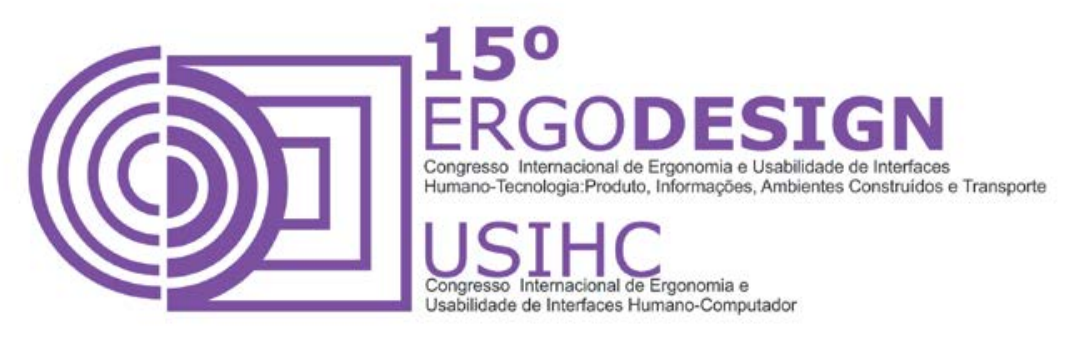

aparecem em seu feed de notícias um texto temporário, contando sobre essa interação, exibindo a foto em questão:

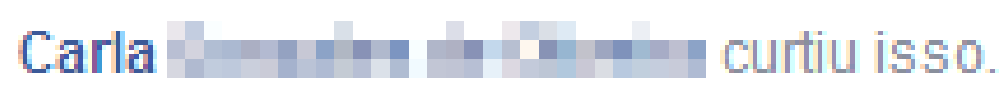

Figura 4 - Exibição temporária de um post curtido por um contato no feed de notícias. Fonte: Os autores.

As configurações de privacidade de cada usuário e de suas publicações são consideradas pelo algoritmo do Facebook, o que altera esse último processo. De qualquer forma, a invisibilidade dessas histórias criadas pelo Facebook, que contam as interações de seus contatos, pode ser vista como um aspecto problemático. Não há um local que exiba quantas pessoas visualizaram aquela história que é exibida temporariamente.

Os 3 aspectos analisados também se aplicam para outras interações tais como: comentários, compartilhamentos e uma nova amizade (a conexão entre perfis), uma página "curtida", entre outras. De forma semelhante, os mesmos processos ocorrem em outros sites de redes sociais. A interação do tipo "curtir" configurou um padrão para as interfaces de SRSs e extrapolou esse contexto atingindo outros tipos de site, até mesmo sites de notícia, que integram botões de SRSs junto às suas publicações. O Google utiliza em seu sistema de busca o +1 (uma espécie de "curtir" do Google Plus) para aprimorar os resultados de pesquisa com base nas avaliações de conexões sociais. Esses exemplos, assim como o "curtir" em si, são apenas a superfície da trama de possibilidades que a integração de interfaces com SRSs oferecem.

\section{CONSIDERAÇÕES}

Neste estudo buscou-se identificar os impactos imediatos do "curtir" como forma de comunicação não verbal entre pessoas no Facebook. Longe de se chegar a qualquer conclusão absoluta sobre o tema, o estudo teve como objetivo analisar o atual contexto da interação reativa nas mídias sociais, especificamente em sites de redes sociais, evidenciados a partir dos exemplos citados. Com base na revisão teórica observou-se que o "curtir" passa de uma simples condição de interação reativa para uma cultura que carrega uma nova forma de comunicação e de consumo de conteúdo. "Curtir" é aprovar sem dizer uma palavra e, mesmo assim, causar registros que impactam sistemas e pessoas.

Um estudo mais profundo com testes com usuários contribuiria para ampliar a compreensão das percepções e motivações dos usuários a respeito da ferramenta. Ficam em aberto outras interações reativas nas mídias sociais, tais como o retweet do Twitter, site de muitas peculiaridades. Os sites Tumblr, Pinterest e Instagram são relevantes no cenário dos SRSs e também dispõem de interações reativas. Outra possibilidade é a exploração do cenário de aplicativos mobile de SRSs, que tem apresentado interações reativas gestuais, por meio de interfaces sensíveis ao toque. 


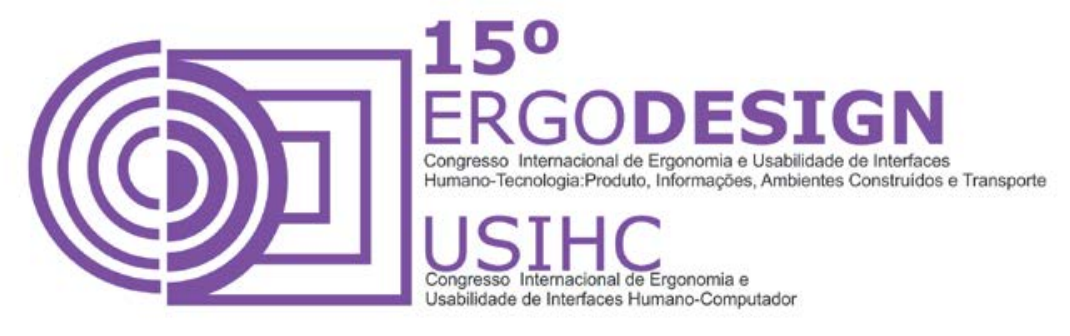

Por fim, ressalta-se que a integração dos SRSs com outros tipos de site é mais uma possibilidade para futuros estudos. A relevância do "curtir" parece estar em sua simplicidade superficial e na complexidade das identidades, redes e capital social envolvidas nessa soma de cliques. Essas características têm grande potencial para o desenvolvimento de interfaces mais significativas, que contribuam para uma melhor experiência dos usuários. Portanto, parece pertinente para o campo do design que se invista em projetos e pesquisas que se dediquem a compreender e dialogar com as mídias sociais.

\section{REFERÊNCIAS BIBLIOGRÁFICAS}

COOPER, A; REIMANN, R; CRONIN, D. About Face 3: The Essentials of Interaction Design. Indianapolis: Wiley Publishing, 2007.

EHRENBERG, R. Science \& Society: What Facebook 'like' reveals: Researchers predict personal traits using social media data. Science News. 2013, vol. 183(8), p 14.

JOHNSON, S. Cultura da Interface: Como o computador transforma nossa maneira de criar e comunicar. Rio de Janeiro: Jorge Zahar, 2001.

PRIMO, A. O que há de social nas mídias sociais? Reflexões a partir da teoria ator-rede. In: Contemporanea: Comunicação e cultura. Salvador, v. 10, n. 3, p.618-641, set-dez. 2014.

PRIMO, A. Interação mediada por computador: Comunicação, cibercultura, cognição. Porto Alegre: Sulina, 2008.

RECUERO, R. Conversação em rede: Comunicação mediada por computador e redes sociais na internet. Porto Alegre: Sulina, 2012.

Redes sociais na internet. Porto Alegre: Sulina, 2009.

SANTAELLA, L. Comunicação ubíqua: repercussões na cultura e na educação. São Paulo: Paulus, 2013.

TORI, R. A presença das tecnologias interativas na educação. In: Revista de Computação e Tecnologia da PUC/SP. São Paulo, v. 2, n. 1, 2010. 